Tiên Lữ năm2011", Tạp chí y học Thực hành, 82(2).

8. Trân Thị Thắm (2016), "Tình trạng dinh dưỡng của trẻ dưới 5 tuổi và kiến thức, thực hành nuối con của bà me huyên Trần Yên, tỉnh Yên Bái năm 2015", Trường Đại học Y Hà Nội tr. 35-57.
9. Lê Thị Hương, Đoàn Thị Ánh Tuyết (2011), "Tình trang dinh dưỡng của trẻ nhỏ dưới 2 tuổi và thực hành nuôi dưỡng trẻ của bà me tai Hướng Hoá và Dakrong năm 2011", Trường Đại học Y Hâ Nội, tr. 20-30.

\title{
ĐÁNH GIÁ KẾT QUẢ PHỤC HỒI KHẢ NĂNG ĐI TRÊN BỆNH NHÂN LIỆT NỬA NGƯờI DO NHỒI MÁU NÃO
}

\section{TÓM TẮT}

Đột quỵ não gây ra nhiều khiếm khuyết, là thách thức không nhỏ cho các nhà thực hành lâm sàng chuyên ngành Phục hồi chức năng. Trong đó chức năng đi là vô cùng quan trọng để bệnh nhân (BN) có thể tham gia vào các hoat động sinh hoạt, lao đông và hội nhập. Mục tiêu: đánh giá kết quả phục hồi khả năng đi trên bệnh nhân liêt nửa người do nhồi máu não. Đối tượng và phương pháp nghiên cứu: Gồm 31 bênh nhân được chẩn đoán liêt nửa người do nhồi máu não lần đầu tiên được điều trị tại Bệnh viện Phục hồi chức năng Hà Nôi từ ngày $01 / 08 / 2020$ đển ngày 30/05/2021. BN được tập luyện phục hồi chức năng (PHCN) tâp trung vào các bài tập tăng khả năng đi trong thời gian 1 tháng tại bệnh viện. Đánh giá sau 2 tuần, 1 tháng khả năng dồn trọng İượng bên liệt, vân tốc đi, nhịp bước đi, chiều dài sải chân, thang điểm khả năng đi FAC và thang điểm Tinetti. Kết quả: Độ tuổi hay gặp là $\geq 60$ chiếm $80,6 \%$, tuổi trung bình $63,6 \pm 9,8$. Tî lệ nam/nữ là 1,38. Tỉ lệ $B N$ liệt nưa người bên phải là $74,2 \%$ và bên trái là $25,8 \%$. Thời gian đột quy trong nhóm nghiên cứu hay gặp là $\leq 12$ tuần chiếm 93,5\%. Sau 1 tháng, khả năng dồn trong lượng chân liệt, thông số nhịp bước đi, chiều dài sải chân và vận tốc đi cải thiện. Khả năng đi FAC độc lập là $51,6 \%$ và điểm Tinetti cũng tăng đáng kể. Kết luận: Phưc hồi chức năng khả năng đi cho bệnh nhân liệt nửa người do nhồi máu não mang lại hiệu quả cải thiện đáng kể, giúp bênh nhân đi laii tốt hơn.

Tư khóa: Phục hồi khả năng đi, nhồi máu não

\section{SUMMARY}

\section{EVALUATION OF THE RESULTS OF WALKING REHABILITATION FOR PATIENTS WITH HEMIPLEGIA DUE TO ISCHEMIC STROKE}

Stroke causes many defects, which is not a small challenge for clinical practitioners specializing in Rehabilitation. In which walking function is extremely important so that the patient can participate in activities of living, working and integrating. Objectives: to evaluate the results of walking ability

\footnotetext{
*Trường Đại học Y Dược Hải Phòng

**Trướng Đai hoc Y Hà Nôi

Chịu trách nhiệm chính: Phạm Văn Minh

Email: pvminhrehab@yahoo.com

Ngày nhận bài: 5.5.2021

Ngày phản biên khoa hoc: 25.6.2021

Ngày duyệt bài: 6.7.2021
}

\section{Nguyễn Thị Huệ*, Phạm Văn Minh**}

recovery in hemiplegic patients due to ischemic stroke. Patients and methodology: Including 31 patients diagnosed with hemiplegia due to ischemic stroke for the first time being treated at Hanoi Rehabilitation Hospital from August 1, 2020 to May 30, 2021. The patient received rehabilitation training focusing on exercises to increase walking ability during 1 month at the hospital. Evaluation after 2 weeks, 1 month of ability to put weight on the paralyzed side, walking speed, walking rate, stride length, FAC scale and Tinetti scale. Results: The common age is $\geq 60$, accounting for $80.6 \%$, the mean age is $63.6 \pm 9.8$. The male/female ratio is 1.38 . The rate of patients with hemiplegia on the right side is $74.2 \%$ and the left side is $25.8 \%$. The common stroke time in the study group was $\leq 12$ weeks, accounting for $93.5 \%$. After 1 month, the ability to weight paralyzed leg, walking cadence, stride length and walking speed improved. The probability of going FAC independently is $51.6 \%$ and the Tinetti score also increases significantly. Conclusion: Rehabilitation of walking ability for patients with hemiplegia due to ischemic stroke brought significant improvement, helping patients to walk better.

Key word: Walking rehabilitation, ischemic stroke

\section{I. ĐĂT VẤN ĐỀ}

Đột quỵ não đang là vấn đề thời sự của y học, không chỉ có tỉ lệ mắc bệnh cao mà còn là nguyên nhân gây tử vong hàng thứ 3 sau ung thư và tim mạch. Hơn thế nữa đột quy não gây ra nhiều khiếm khuyết, là thách thức không nhỏ cho các nhà thực hành lâm sàng chuyên ngành Phục hồi chức năng. Theo phân loại của Tổ chức Y tế thế giới thì người bệnh liệt nửa người do đột quy não thuộc loại đa tàn tật. Trong đó, giảm hoặc mất chức năng vận động chi dưới làm bệnh nhẩn phải sống phụ thuộc một phần hoặc hoàn toàn vào người khác.

Chức năng đi lại là vô cùng quan trọng để $\mathrm{BN}$ có thể tham gia vào các hoạt động sinh hoạt, lao động và hội nhập tuy nhiên sau đột quỵ khả năng đi bị giảm sút rất nhiêu. BN thay đổi về khả năng dồn trọng lượng bên liệt, các thông số đi, cơ lực, trương lực cớ, khó giữ thăng bằng và dáng đi khiến BN có dáng đi đặc trưng. Những thay đổi này làm khả năng đi không vững chắc 
và an toàn, tăng nguy cơ ngã. Vì vậy vấn đề PHCN vận động chi dưới cũng như khả năng đi là mối quan tâm cấp thiết cân thực hiện có chiến lược, lâu dài, toàn diện để hạn chế các di chứng, tăng khả năng di chuyển và hòa nhập cộng đồng. Trước đây đã có một số nghiên cứu chỉ ra rằng tập luyện $\mathrm{PHCN}$ giúp cải thiện khả năng đi. Nghiên cứu Trần Văn Chương (2003) chỉ ra khả năng đi độc lập tăng lên 82,8\% sau 1 năm [1]. Năm 2011, Nguyễn Thị Ngọc Lan nghiên cứu trên 66 BN nhồi máu não cũng cho thây tăng khả năng đi lại độc lập và giảm khả năng đi lại phụ thuộc một phần và phụ thuộc hoàn toàn [2]. Tuy nhiên, hiện nay thực sự chưa có nhiều nghiên cứu đánh giá kết quả khả năng đi ở $B N$ đột quỵ. nhồi máu não. Vì vậy chúng tôi tiến hành nghiên cứu này nhằm đánh giá kết quả phục hồi khả năng đi trên BN liệt nửa người do nhồi máu não.

\section{II. ĐỐI TƯợNG VÀ PHƯƠNG PHÁP NGHIÊN CỨU}

2.1 Đối tượng nghiên cứu: Gồm $31 \mathrm{BN}$ được điều trị tại Bệnh viện PHCN Hà Nội từ ngày $01 / 08 / 2020$ đến ngày $30 / 05 / 2021$

- Tiêu chuẩn lựa chon:

+ BN đủ điều kiện chẩn đoán liệt nửa người do đột quỵ nhồi máu não lần đâu tiên

+ Đứng không cần trợ giúp

+Điểm nhân thức MoCA $\geq 18$ điểm.

+Trương lực cơ chi dưới theo thang điểm Ashworth cải biên $\leq 2$ điểm

- Tiêu chuẩn loại trừ:

+ Có khuyết tật về vận động chi bên liệt trước khi xuất hiện đột quy.

+ Có mắc các bệnh lý động kinh, tim mạch không ổn định.

+ Tái phát đột quy hoặc tử vong trong thời gian nghiên cứu.

\subsection{Phương pháp nghiên cứu:}

2.2.1 Tập luyện phục hồi chức năng. $B N$ được tập luyện PHCN khả năng đi tập trung vào các bài tập đứng, tập đi [4] trong thời gian 1 giờ/ngày x 5 ngày/tuân trong 1 tháng tại viện. Ngoài ra $\mathrm{BN}$ vẫn được kết hợp điều trị bằng các kĩ thuật PHCN khác theo chỉ định điêu trị của khoa phòng. BN được đánh giá tại 3 thời điểm: bắt đầu (LO), sau 2 tuần (L1) và sau 1tháng (L2).

\subsubsection{Các chỉ số đánh giá}

- Đặc điểm chung của đối tượng nghiên cứu: tuổi, giới, vị trí bên liệt, thời gian bị đột quy.

- Đánh giá khả năng dồn trọng lượng bên liệt Sức dôn trợng lượng bên chân liệt (kg)

$=$

$$
\text { Tởng cânnăng cơ thê ( } \mathrm{kg} \text { ) }
$$

Dưới 30\%: Kém

$$
\text { x } 100 \%
$$

Từ 30-49\%: Trung bình

Từ 50-70\%: Khá

Từ 71-90\%: Tốt

Trên 90\%: Rất tốt

- Đánh giá vận tỗc đi trên quãng đường 10 Qưãng đường

$$
\begin{gathered}
\text { mét. Vận tốc }=\text { Thời gian }(\mathrm{m} / \mathrm{s}) \\
\text { - Đánh giá nhịp bước đi } \\
\text { Số bước chân } x 60(\text { giây })
\end{gathered}
$$

= Thời gian đi hết quãng đường $10 \mathrm{~m}$ (giây)

(bước/phút)

- Đánh giá chiều dài sải chân của BN (m)

- Thang điểm Tinetti: gồm thang điểm thăng bằng, dáng đi và tổng điểm Tinetti

Tổng điểm Tinetti <18: nguy cơ ngã cao, 1923: nguy cơ ngã trung bình, $\geq 24$ : nguy cơ ngã thấp.

- Đánh giá chức năng đi theo Functional Ambulation Categories (FAC)

Không chức năng đi: 0 điểm

Phụ thuộc mức độ 2: 1 điểm

Phụ thuộc mức 1: 2 điểm

Phụ thuộc giám sát: 3 điểm

Độc lập mức nền phẳng: 4 điểm

Độc lập hoàn toàn: 5 điểm

\section{KẾT QUẢ NGHIÊN CỨU}

3.1. Đặc điểm của đối tượng nghiên cứu

- Độ tuổi hay gặp là $\geq 60$ chiếm $80,6 \%$, tuổi trung bình $63,6 \pm 9,8$ dao động từ 34-77. Tỉ lệ nam/nữ là 1,38 , tỉ lệ liệt nửa người bên phải là $74,2 \%$ và bên trái là $25,8 \%$.

- Thời gian đột quy trong nhóm nghiên cứu hay gặp là $\leq 12$ tuần chiếm 93,5\%.

\section{2. Đánh giá khả năng đi trên BN liệt nửa người do nhồi máu não.}

Bảng 3.1. Khả năng dồn trọng lượng lên chân liệt qua các thời điểm đánh giá

\begin{tabular}{|c|c|c|c|c|}
\hline Dồn trọng lượng & LO (\%) & L1 (\%) & L2 (\%) & p \\
\hline Trung bình & 58 & 45,1 & 22,5 & $\mathrm{p}<0,05$ \\
\hline Khá & 25,8 & 32,2 & 51,6 & $\mathrm{p}<0,05$ \\
\hline Tốt & 16,2 & 22,7 & 25,9 & $\mathrm{p}<0,05$ \\
\hline
\end{tabular}

Nhận xét: Như vậy khả năng dồn trọng lượng chân liệt có cải thiện tại các thời điểm sau tập PHCN 2 tuần và 1 tháng , đặc biệt rõ rệt sau 1 tháng với mức trung bình từ $58 \%$ xuống còn $22,5 \%$, mức khá tăng từ $25,8 \%$ lên $51,6 \%$ và có ý nghĩa thống kê với $p<0,05$. 
Bảng 3.2. Các thông số đi

\begin{tabular}{|c|c|c|c|c|}
\hline Thông số đi & L0 & L1 & L2 & P \\
\hline Vận tốc đi & $0,292 \pm 0,02$ & $0,301 \pm 0,02$ & $0,318 \pm 0,03$ & $\mathrm{p}<0,01$ \\
\hline Nhịp bước đi & $54,45 \pm 5,25$ & $55,71 \pm 4,89$ & $57,74 \pm 5,71$ & $\mathrm{p}<0,01$ \\
\hline Chiều dài sải chân & $0,514 \pm 0,056$ & $0,531 \pm 0,053$ & $0,558 \pm 0,054$ & $\mathrm{p}<0,01$ \\
\hline
\end{tabular}

Nhận xét: Các thông số về dáng đi có cải thiện sau 1 tháng với $\mathrm{p}<0,01$ nhưng vẫn giảm so với người bình thường. Vận tốc đi $(\mathrm{m} / \mathrm{s})$ tại thời điểm L0 là $0,292 \mathrm{~m} / \mathrm{s}$, sau 1 tháng là 0,318 . Nhịp bước đi (bước/phút) taai thời điểm L0 là 54,45 bước/phút, sau 1 tháng là $57,74 \mathrm{~m}$. Chiêuu dài sải chẩn $(\mathrm{m})$ tại thời điểm LO là $0,514 \mathrm{~m}$, sau 1 tháng là $0,558 \mathrm{~m}$.

Bảng 3.3. Điểm Tínetti trung bình tại các thời điểm đánh giá

\begin{tabular}{|c|c|c|c|}
\hline Thời điếm đánh giá & Thăng bằng $(X \pm S D)$ & Dáng đi $(X \pm S D)$ & Tống Tinetti $(X \pm S D)$ \\
\hline$L 0$ & $10,81 \pm 2,84$ & $4 \pm 1,98$ & $14,84 \pm 4,60$ \\
\hline$L 1$ & $11,71 \pm 2,70$ & $5,42 \pm 1,76$ & $17,16 \pm 4,25$ \\
\hline$L 2$ & $14,10 \pm 2,21$ & $7,19 \pm 1,62$ & $21,23 \pm 3,35$ \\
\hline$p$ & $p<0,01$ & $p<0,01$ & $p<0,01$ \\
\hline
\end{tabular}

Nhận xét: Kết quả điểm tổng Tinetti có cải thiện tại: lúc băt đâu tập là 14,84 $\pm 4,60$ điểm, sau 1 tháng tăng lên $21,23 \pm 3,35$ điểm. Sự cải thiện này là có ý nghĩa thông kê với $p<0,01$.

Bảng 3.4. Kêt quả phục hồi chức năng khả năng đi theo FAC

\begin{tabular}{|c|c|c|c|}
\hline Điếm FAC & LO (\%) & L1 (\%) & L2 (\%) \\
\hline 2 & 16,2 & 16,2 & 9,7 \\
\hline 3 & 64,5 & 54,8 & 38,7 \\
\hline 4 & 19,3 & 29,0 & 51,6 \\
\hline$p$ & \multicolumn{3}{|c|}{$\mathrm{p}<0,05$} \\
\hline
\end{tabular}

Nhận xét: Sau 1 tháng kết quả khả năng đi độc lập mức nền phẳng tăng lên $51,6 \%$ và có ý nghĩa thống kê với $p<0,05$.

\section{BÀN LUÂN}

4.1.Đặc điểm của đối tượng nghiên cứu

- Trong 31 BN nghiên cứu $B N$ có tuổi thấp nhất là 34 tuổi, cao tuổi nhất là 77 , tuổi trung bình $63,6 \pm 9,8$, nhóm tuổi $\geq 60$ chiếm tỉ lệ cao nhất $80,6 \%$. Tỉ lệ nam/nữ là 1,38. Kết quả nghiên cứu phù hợp với các tác giả trong và ngoài nước, Trân Văn Chương [1] nhóm tuổi 60-69 gặp nhiều nhất, nam/nữ là 1,7 . Nghiên cứu của Van Criekinge T có độ tuổi trung bình 63,6 2 14,4 [5].

- Tî lệ liệt liệt nửa người bên phải chiếm $74,2 \%$, bên trái chiếm $25.8 \%$. Tuy nhiên kết quả Trần Văn Chương [1] thấy không có sự khác biệt đáng và Van Criekinge $T$, bên phải chiếm $35 \%$ và bên trái là $65 \%$ [5]. Chúng tôi cho rằng sự khác nhau này có thể do cách chọn, số lượng BN nghiên cứu của các tác giả không giống nhau.

- Thời gian đột quy trong nhóm nghiên cứu hay gặp là $\leq 12$ tuần chiếm $93,5 \%$. Kết quả này là phù hợp với các tác giả như Trần Văn Chương. Sự phục hồi vận động của đột quỵ không phải là một đường thẳng mà theo đường cong và hầu hết phục hồi xảy ra trong những ngày tháng đâu tiên đặc biệt trong 3 tháng đầu theo cơ chế tính mềm dẻo thần kinh của não bộ. Vì vậy nhóm nghiên cứu của chúng tôi vẫn nằm trong khoảng

thời gian vàng để hồi phục vận động.

\subsection{Khả năng dồn trơng lượng lên chân} liệt qua các thời điểm đánh giá. Về khả năng dổn trọng lượng chân liệt, Phạm Thị Minh Nguyệt thấy sau 1 tháng tập luyện có sự cải thiện rõ rệt với mức tốt với 41,5\%, mức khá từ $70,7 \%$ giảm xuống còn 46,3\% [3]. Với nghiên cứu của chúng tôi cũng thấy có cải thiện tại các thời điểm và rõ rệt sau 1 tháng với mức trung bình từ $58 \%$ xuống còn $22,5 \%$, mức khá tăng lên $51,6 \%$, mức tốt tăng lên $25,9 \%$ và khác biệt có ý nghĩa thống kê với $\mathrm{p}<0,05$.

\subsection{Các thông số đi}

- Về vận tốc đi, Jerome GJ thấy rằng vận tốc đi của người cao tuổi $1,1 \pm 0,2 \mathrm{~m} / \mathrm{s}$ [6], Phạm Thị Hải Yến là $0,96 \pm 0,01 \mathrm{~m} / \mathrm{s}$ với nhóm chứng và nhóm bệnh nhân đột quy là $0,31 \pm 0,19 \mathrm{~m} / \mathrm{s}$ [7]. Nghiên cứu của Phạm Thị Minh Nguyệt sau can thiệp tập luyện $\mathrm{PHCN} 1$ tháng là $0,495 \pm$ $0,091 \mathrm{~m} / \mathrm{s}$, tăng so với trước can thiệp [3]. Kết quả nghiên cứu của chúng tôi cho thấy $\mathrm{BN}$ sau đột quy có vận tốc đi thấp hơn so với người bình thường và phù hợp với kết quả nghiên cứu của các nghiên cứu trền. Tại bảng 2, vận tốc đi trung bình sau 1 tháng là $0,318 \pm 0,03 \mathrm{~m} / \mathrm{s}$ tăng so với thời điểm bắt đầu tập $0,292 \pm 0,02 \mathrm{~m} / \mathrm{s}$ và có ý nghĩa thống kê với $p<0,01$.

- Về nhịp bước đi, Jerome $\mathrm{G}$ nghiên cứu trên người cao tuổi có nhịp bước đi là $112,8 \pm 8,7$ bước/phút [6]. Phạm Thị Hải Yến cũng thấy $B N$ sau đột quy. có nhịp bước đi là $54,61 \pm 13,7$ giảm so với người bình thường [7], còn Phạm Thị Minh Nguyệt trước can thiệp là 57,942 \pm 4,302 và sau 1 tháng nhịp bước đi tăng lên đến $68,022 \pm 5,247$ [3]. Tại bảng 2 cho thấy nhịp bước đi trung bình giảm so với người bình 
thường và sự cải thiện phù hợp với các nghiên cứu trên, tại thời điểm trước can thiệp là 54,45 $\pm 5,25$, sau 1 tháng tăng lên $57,74 \pm 5,71$ bước/ phút. Sự khác biệt có ý nghĩa thống kê với $p<0,01$.

- Về chiêu dài sải chân, Jerome $\mathrm{GJ}$ thấy rằng ở người cao tuổi là $1,2 \pm 0,2 \mathrm{~m}$ [6], Phạm Thị Hải Yến là $1,01 \pm 0,1 \mathrm{~m}$ với nhóm chứng và 0,37 $\pm 0,01 \mathrm{~m}$ với nhóm bệnh [7]. Phạm Thị Minh Nguyệt (2008) có chiều dài sải chân khi đi giảm hơn so với người bình thường và có cải thiện sau 1 tháng[3]. Trong kết quả nghiên cứu của chúng tôi tại bảng 2 cho thấy chiều dài sải chân trung bình giảm so với người bình thường, tại thời điểm trước can thiệp là $0,514 \pm 0,056 \mathrm{~m}$, sau 1 tháng tăng lên $0,558 \pm 0,054 \mathrm{~m}$ và có ý nghĩa thống kê với $p<0,01$. Kết quả này là phù hợp với các nghiên cứu trên.

4.4. Điểm Tinetti trung bình tại các thời điểm đánh giá. BN sau đột quy khả năng vận động hạn chế, khó khăn trong việc phối hợp và điêu chỉnh tư thế, cũng như khó giữ thăng bằng và dáng đi. Van Criekinge $T$ [5] nghiên cứu trên BN được đột quy trong vòng 5 tháng với nhóm nghiên cứu (19 BN) được tập luyện các bài tập thân mình, với nhóm chứng (20 BN) được tập luyện các bài tập nhận thức và không có bài tập thân mình. Cả 2 nhóm đều tập luyện 1 giờ/ngày, 4 ngày/tuần và trong thời gian 4 tuần. Van Criekinge $T$ kết luận các bài tập thân mình có tác dụng cải thiện điểm Tinetti bao gồm cả thăng bằng và dáng đi. Trong nghiên cứu của chúng tôi, điểm tổng Tinetti cũng có cải thiện tại các thời điểm đặc biệt sau 1 tháng tập luyện tăng từ $14,84 \pm 4,60$ điểm lên $21,23 \pm 3,35$ điểm và sự cải thiện có ý nghĩa thống kê với $p<0,01$.

4.5. Kết quả phục hồi chức năng khả năng đi theo FAC. Khả năng đi độc lập theo nghiên cứu Trần Văn Chương là $83 \%$ sau 12 tháng [1], Phạm Thị Minh Nguyệt là 83\% [3], Nguyễn Thị Ngọc Lan là $66,7 \%$ sau 3 tháng [2], còn nghiên cứu của chúng tôi là $51,6 \%$. Kết quả của chúng tôi thấp hơn so với các nghiên cứu trên có thể do thời gian nghiên cứu ngẳn.

\section{KẾT LUÂN}

PHCN khả năng đi cho BN liệt nửa người do nhồi máu não mang lại hiệu quả cải thiện đáng kể, giúp BN đi lại tốt hơn.

\section{TÀI LIẸU THAM KHẢO}

1. Trânn Văn Chương (2003), Nghiên cứu phương pháp phục hồi chức năng vận động cho bệnh nhân liệt nửa người do tai biến mạch máu não, Luận án tiến sĩ y học, Trường Đại Hoc Y Hà Nội.

2. Nguyển Thị Ngọc Lan, Nguyển Thị Kim Thửy (2011). Đánh giá kết quả phục hồi chức năng vận đông của bênh nhân nhồi máu não cấp bằng kỹ thuật Bobath. Y học thực hành, (12), 100-103.

3. Phàm Thi Minh Nguyêt, Trân Văn Chương (2008), Đánh giá kêt quả phục hồi chức năng đỉ lại và mối liên quan với cơ lực chi dưới ở bệnh nhân tai biến nhôi máu não vùng bán cầu, Luận văn thạc sĩ y khoa, Trường Đaai học Y Hà Nội.

4. Bộ Y Tế (2014), Hướng dẩn quy trình kĩ thuật chuyên ngành phục hồi chức năng, 87 - 89

5. Van Criekinge T., Hallemans A., Herssens $\mathbf{N}$. và CS (2020). SWEAT2 Study: Effectiveness of Trunk Training on Gait and Trunk Kinematics After Stroke: A Randomized Controlled Trial. Physical Therapy, 100(9), 1568-1581.

6. Jerome G.J., Ko S., Kauffman D. và CS (2015). Gait Characteristics Associated with Walking Speed Decline in Older Adults: Results from the Baltimore Longitudinal Study of Aging. Arch Gerontol Geriatr, 60(2), 239-243.

7. Phạm Thị Hải Yến (2002), Nghiên cứu một số thay đổi về dáng đi trên bệnh nhân liệt nửa người sau tai biến mạch máu nã̃o vùng bán câu, Luận văn bác sĩ nội trú, Trường Đại học Y Hà Nội.

\section{ĐĂ̆C ĐIỂM GIẢI PHẪU DIỆN BÁM GÂN DƯớI VAI NGƯỜI VIỆT NAM TRƯỞNG THÀNH ỨNG DỤNG TRONG PHẪU THUẬT}

\section{Nguyễn Hữu Mạnh 1,4, Trần Trung Dũng ${ }^{2,4}$, Lê Khánh Trình ${ }^{3}$}

\section{TÓM TẮT}

\author{
${ }^{1}$ Trường Đại học Y Dước Đại học Quốc Gia Hà Nội, \\ ${ }^{2}$ Trường Đại học Y Hà Nội, \\ ${ }^{3}$ Bệnh viện E Trung Ương, \\ ${ }^{4}$ Bềnh viến Đa Khoa Tâm Anh \\ Chịu trách nhiệm chính: Nguyễn Hữu Mạnh \\ Email: manhnguyen0901@gmail.com \\ Ngày nhận bài: 10.5.2021 \\ Ngày phản biên khoa học: 25.6.2021 \\ Ngày duyệt bài: 5.7.2021
}

Tổng quan: Phẫu thuật nội soi khâu gân dưới vai rách rất quan trọng trong việc phục hồi giải phẫu và giúp khớp vai đạt được chức năng tốt nhất, có nhiều nghiên cứu thực cho thấy sự hiệu quả của phương pháp khâu một hàng sử dụng mũ̃i khâu Mason-Allen cải biên. Hiện các nghiên cứu về giải phẫu diện bám gân dưới vai vào củ bé còn ít, chủ yếu tập trung nhiều vào kích thước và hình dạng, thiếu sự xác định các mối liên quan giữa các đặc diểm của diện bám và giữa các đặc điểm này với các mốc giải phấu quan trọng có thể áp dụng trên thực tế lâm sàng để giúp cho quá trình khâu phục hồi gân chính xác. Đối tượng và 